\title{
Internal radio-echo layering at Vostok station, Antarctica, as an independent stratigraphic control on the ice-core record
}

\author{
Martin J. Siegert, ${ }^{1}$ Richard Hodgkins, ${ }^{2}$ Julian A. Dowdeswell ${ }^{3}$ \\ ${ }^{1}$ Centre for Glaciology, Institute of Geography and Earth Sciences, University of Wales, Aberystwyth Sr23 3DB, Wales \\ ${ }^{2}$ Department of Geography, Royal Holloway, University of London, Egham, Surrey TW20 0EX, England \\ ${ }^{3}$ School of Geographical Sciences, University of Bristol, Bristol BS8 1SS, England
}

\begin{abstract}
Antarctic radio-echo sounding (RES) data at $60 \mathrm{MHz}$ have been used to determine an independent stratigraphy for the ice core at Vostok station, based on internal radio-echo layering. A-scope RES data allow the amplitude of reflected electromagnetic $(\mathrm{e} / \mathrm{m})$ waves to be measured and, by accounting for geometric spreading and absorption losses of the $\mathrm{e} / \mathrm{m}$ wave, power reflection coefficients (PRCs) to be calculated. This information is compared with time-continuous Z-scope RES data in order to trace continuous $\mathrm{e} / \mathrm{m}$ reflectors across the ice sheet. Internal ice-sheet horizons deeper than $800 \mathrm{~m}$ are caused by layers of ice that possess distinctly different dielectric properties (i.e. acidic layers) compared with ice above and/or below. Comparison of four PRC samples, located $\sim 5 \mathrm{~km}$ from Vostok station, revealed five distinct internal reflections between 1000 and $2200 \mathrm{~m}$. Z-scope data from directly over the Vostok station site show the same five prominent internal radio-echo layers. The depth-related radio-echo signals were then compared with chemical records from the Vostok ice core, including the $\mathrm{H}_{2} \mathrm{SO}_{4}$ signal, a major component of which is derived from volcanic events. From this procedure, internal radio-echo reflectors and Vostok ice-core acid measurements were correlated. Avery good match was made between Z-scope and ice-core data. However, vertical offsets observed between A-scope-derived RES layers and peaks in the chemical signal of up to $100 \mathrm{~m}$ are probably due to the general folding of the ice-sheet layering between the core site and the RES flight-line. We conclude that $60 \mathrm{MHz}$ RES layering may be regarded as a stratigraphy independent of palaeoclimate, and may be used to correlate other deep Southern Hemisphere ice cores.
\end{abstract}

\section{INTRODUCTION AND BACKGROUND}

Antarctic radio-echo sounding (RES) data, acquired at $60 \mathrm{MHz}$, show a number of strong reflections from within the ice sheet. Several individual internal reflectors are discrete and continuous over large $(>100 \mathrm{~km})$ distances. Such electromagnetic $(\mathrm{e} / \mathrm{m})$ reflections in ice occur at boundaries of dielectric contrast. The causes of the reflectors are thought to be (1) ice-density changes, to a depth of $\sim 800 \mathrm{~m}$, and (2) acidic layers of ice derived from atmospheric aerosol products (including volcanic-derived material). Consequently, below $800 \mathrm{~m}$, internal radio-echo layering is caused mainly by acidic layering within the ice sheet (Millar, 1981).

An extensive analogue radio-echo sounding dataset of the Antarctic ice sheet, collected by the SPRI (Scott Polar Research Institute)-NSF(U.S. National Science Foundation)-TUD (Technical University of Denmark) consortium between 1968 and 1979, is held in archive at SPRI, University of Cambridge, U.K.. Approximately $50 \%$ of the ice sheet is covered by RES flight-tracks. A significant proportion of these data were collected over the eastern half of East Antarctica, including several flight-lines over the Vostok station area (Fig. 1).

During the 1980s, a deep ( $\sim 2400 \mathrm{~m})$ ice core was taken from a site in close proximity to Vostok station. An unprecedented palaeoclimate record resulted from interpretation of the Vostok ice core (e.g. Barnola and others, 1987). However, the ice-core data have yet to be compared directly with RES data collected near the coring site. Previous correlations between ice-core data and RES information have proven valuable for the interpretation of ice-core data and the glaciology of central regions of ice sheets (e.g. Moore, 1988;

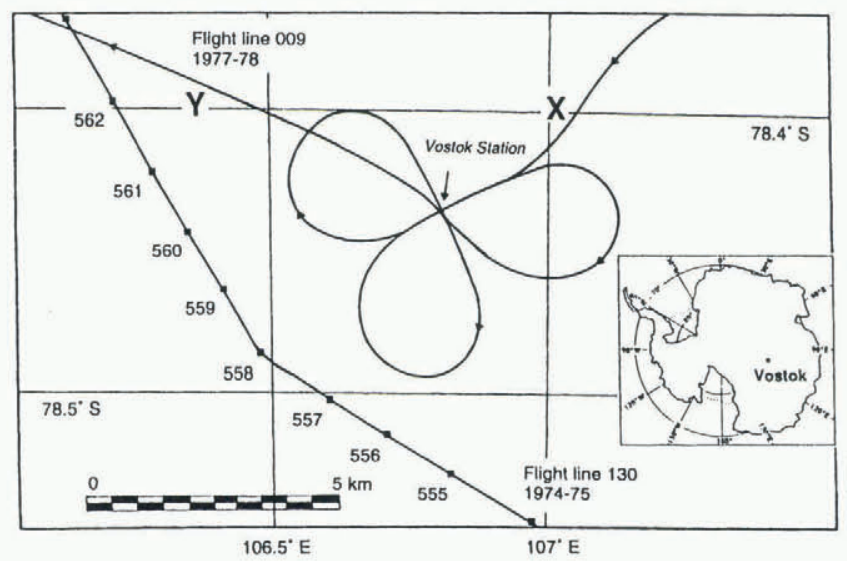

Fig. 1. The location of Vostok station and position of RES flight-lines 130 and 009. Note that flight 009 passes over Vostok station four times. The locations of $A$-scopes recorded along line 130 are identified as $C B D$ numbers $(1 C B D=15$ s flight time). Markers $X$ and $Y$ refer to the beginning and end of the RES section in Figure 3. The location of Vostok station in Antarctica is given in the inset. 


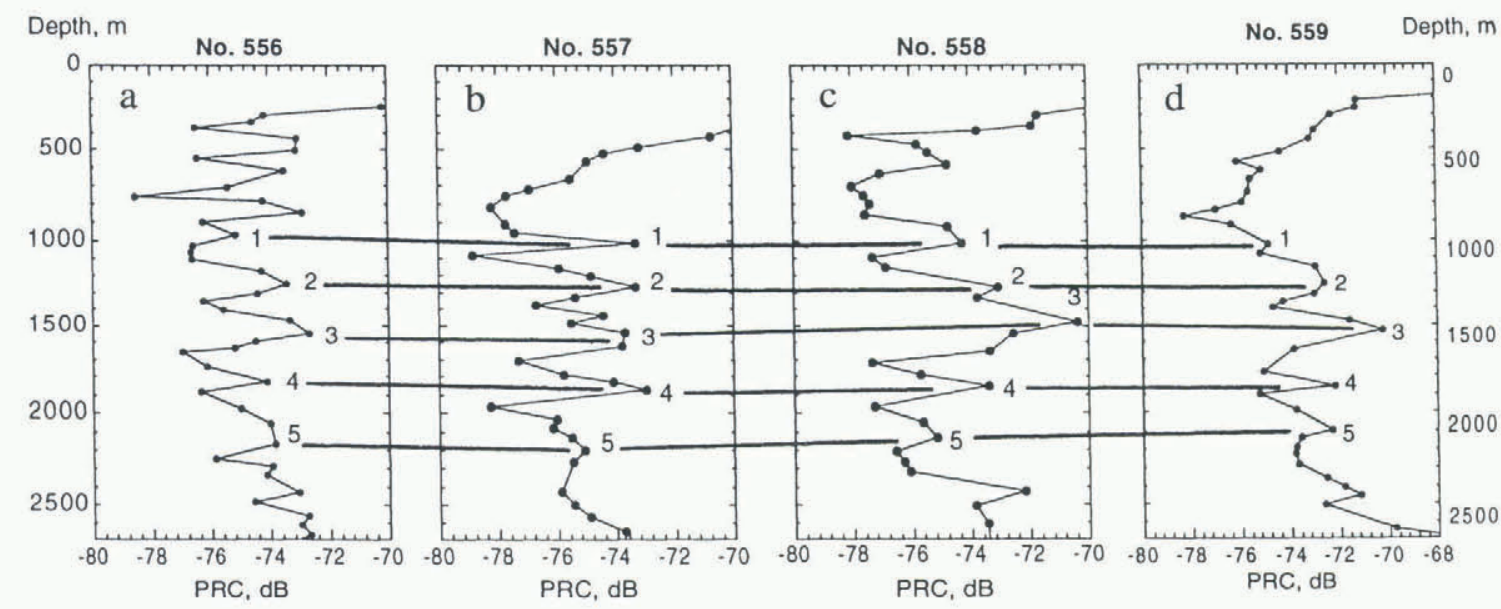

\begin{abstract}
Fig. 2. PRC information derived from A-scope RES data. The locations of the PRCs are shown in Figure 1. PRC nos. 556 (a), 557 (b), 558(c) and 559(d). Note that five distinct PRC maxima are identified on each record, and correlated across the PRC dataset.
\end{abstract}

Hvidberg and others, 1997). In this paper, we analyze $60 \mathrm{MHz}$ RES data from Vostok station in order to provide a complete record of the internal RES signal. These RES data are compared with ice-chemistry information gathered from previous analyses of the Vostok ice core. Our results now make it possible to compare the Vostok ice core with other Antarctic ice cores using radio-echo sounding information.

\section{THE NATURE AND ANALYSIS OF INTERNAL RADIO-EGHO LAYERS}

RES data were recorded in two different formats during Antarctic RES operations. The first comprises graphs of two-way travel time vs signal strength from single e/m pulses, known as A-scopes, recorded every 15 seconds (or each CBD unit). The second form represents a series of single $\mathrm{e} / \mathrm{m}$ returns, collected in a time-dependent manner in which signal strength is identified by brightness rather than an axis variable. When plotted as two-way e/m wave travel-time vs real time, these time-dependent data yield pseudo-cross-sections of the ice sheet, or Z-scope data (Fig. 2). Internal radio-echo layering can be identified, and traced across the ice sheet, from analysis of both types of record. Quantitative information about the reflectivity of individual layers can be gained by processing A-scope data to determine power reflection coefficients (PRCs).

PRCs are calculated from A-scope data that are adjusted to account for geometric spreading, refraction and dielectric absorption of radio waves in ice, and two-way antenna gain of the RES apparatus (Robin, 1969; Paren, 1981). The equation used is:

$$
R=P-G+20 \log \left\{\frac{\lambda_{0}}{8 \pi\left[r_{0}+(h / n)\right]}\right\}+D
$$

where $R$ is the PRC, $P$ is the amplitude of the received radio wave relative to the transmitted power, $G$ is the two-way antenna gain, $D$ is the dielectric absorption, and the remaining term denotes geometric spreading and refraction of radio waves in ice (where $\lambda_{0}$ is the radio wavelength in air, $h$ is the ice depth of an internal layer, $r_{0}$ is the terrain clearance of the aircraft and $n$ is the refractive index of ice). Note that $P, G, D, R$ and the geometric spreading term are in units of $\mathrm{dB}$, i.e. they are logs of power ratios.
According to Millar (1982), PRCis from a single ice layer at depths of $>800 \mathrm{~m}$, where contrast in the real part of the dielectric constant can be ignored, can be related to the "loss tangent" difference between the layer and the surrounding ice $(\Delta \tan \delta)$, by the equation:

$$
R=0.25 \sin ^{2}\left(\frac{2 \pi l}{\lambda}\right) \cdot(\Delta \tan \delta)^{2}
$$

where $\lambda$ is the radio wavelength in ice and $l$ is the ice-layer thickness. Equation (2) holds if $l$ is less than $0.25 \lambda$. The loss tangent is related to high-frequency conductivity, $\sigma_{\infty}$, by:

$$
\tan \delta=\frac{\sigma_{\infty}}{2 \pi f \epsilon_{0} \epsilon_{\mathrm{i}}}
$$

where $\epsilon_{0}$ is the permittivity of free space, $\epsilon_{\mathrm{i}}$ is the permittivity of the ice, and $f$ is the radar frequency. Thus, the difference in high-frequency conductivity $\left(\Delta \sigma_{\infty}\right)$ between a radio-echo layer and the surrounding ice can be calculated from $R$.

It should be noted that the reflecting horizons responsible for radio-echo layers are probably not single layers but rather groups of closely spaced layers of ice (Harrison, 1973; Millar, 1982). A second point to note is that PRCs are determined from a digitised version of A-scope maxima, and thus represent an upper envelope of power returns. Thus, each data point displayed in the PRC graph corresponds with an A-scope peak.

\section{THE INTERNAL RADIO-EGHO LAYER SIGNAL AT VOSTOK}

A-scope and Z-scope RES data are available for the Vostok station region (Kapitsa and others, 1996). A-scope data were acquired during a 1974 flight near ( $<5 \mathrm{~km}$ from) Vostok station, whilst Z-scope data were collected during a 1977 pass directly over the station. Flight 130/1974 passed from the south to the west of Vostok station, whilst flight 009/1977 passed four times directly over the station during a traverse from east to west (Fig. 1). Two issues arise from our use of the data collected during these particular flights. The first is that we can compare the results from two independent datasets. Consequently, correlation between Z-scope and Ascope data will indicate the robustness of our analysis and the applicability of our work to other regions of Antarctica and other RES data. The second is that Z-scope data from 


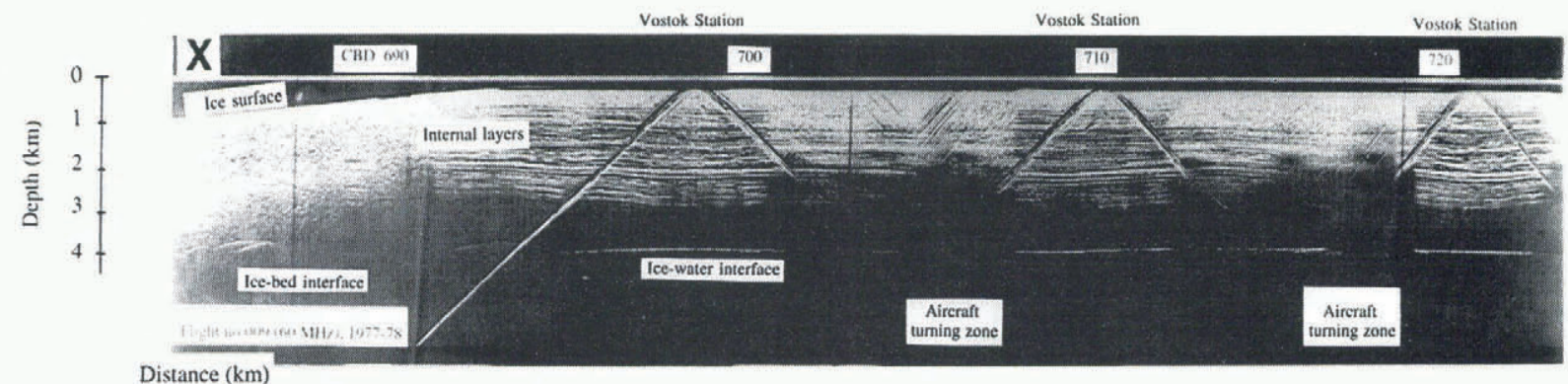

Distance $(\mathrm{km})$
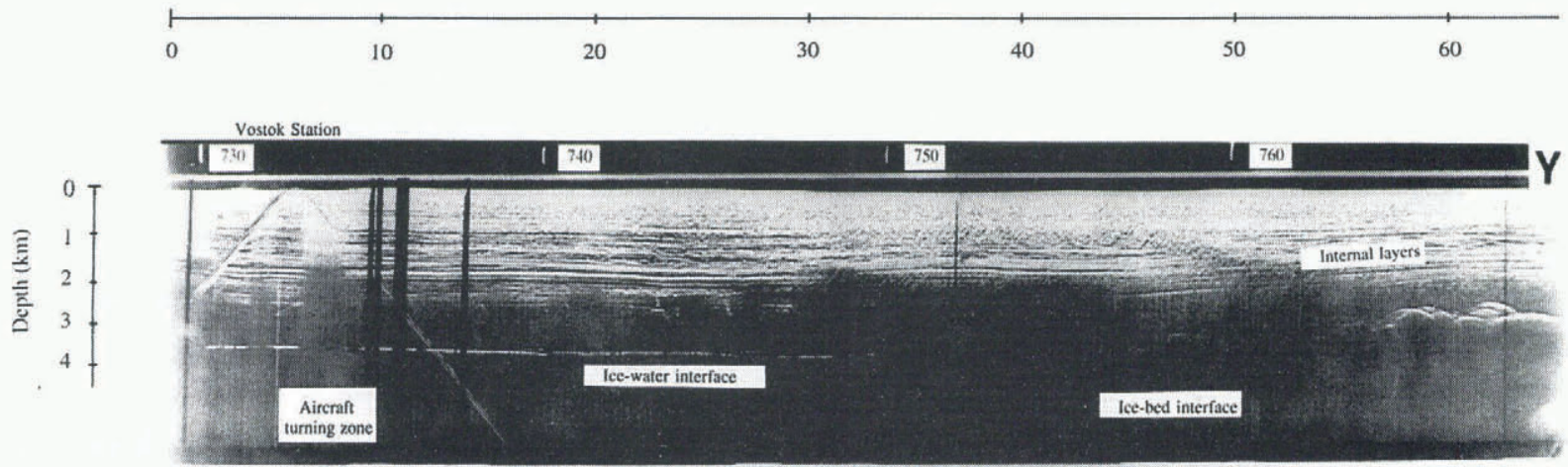

70

80

90

100

110

120

130

Fig. 3. Time-continuous, Z-scope data around Vostok station, during four successive passes over the station buildings (indicated by surface hyperbolae). The diagram illustrates how variation in orientation of the aircraft produces variation in the recorded RES signal. The location of markers $X$ and $Y$ is shown in Figure 1.

flight 009/1977 were recorded directly over Vostok station along four different flight-line orientations (Fig. 1). Variation in the Z-scope data from these four passes indicates the relation between radio-echo reflections and orientation that is inherent in Antarctic RES data.

Because internal ice layers are observed to fold gently with horizontal distance (see Z-scope data in Fig. 3), it is inappropriate to combine PRC calculations from separateA-scope data since there may be no exact common depth relationship (although an approximate one should exist). Consequently, we avoid unwanted smoothing of the PRC signal by not combining data calculated from individual A-scopes together.

In order to examine whether internal radio-echo horizons can be traced across the ice sheet through consideration of A-scope data alone, four PRC records from adjacent A-scope data were compared (Fig. 2). Five distinct PRC maxima corresponding with obvious internal layers can be observed in all PRG records (Fig. 2). In record no. 557, the first of these layers is at $\sim 1000 \mathrm{~m}$ and the fifth is at $\sim 2100 \mathrm{~m}$ (Fig. 2). The exact depth of the radio-echo layers varies by a few tens of metres between each CBD site (Fig. 2), indicating a gentle undulation of internal layering with horizontal distance. Due to the PRC strength of these layers, and because they can be traced continuously over several $\mathrm{km}$, we conclude that these five horizons (1) represent distinct radioecho markers within the ice column and (2) will be evident in adjacent regions of the ice sheet.

Z-scope data from Vostok station indicate further how internal layers can be traced continuously across the ice sheet (Fig. 3). Several prominent internal layers are traceable across the full extent of the Z-scope section in Figure 3.

The surface parabola on the Z-scope signal indicates $\mathrm{e} / \mathrm{m}$ reflections off Vostok station buildings, and so locates accurately the position of the station with respect to the tra-

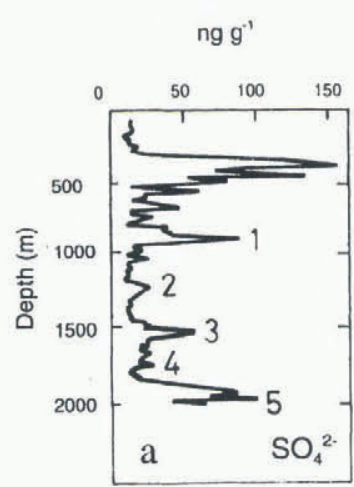

$\mathrm{ng} \mathrm{g}^{\prime}$

$\mu \mathrm{Eq} \mathrm{I}^{\prime}$

$\mu \mathrm{El}^{-1}$

PRC (dB)

$\mu \mathrm{E} \mathrm{I}^{-1}$
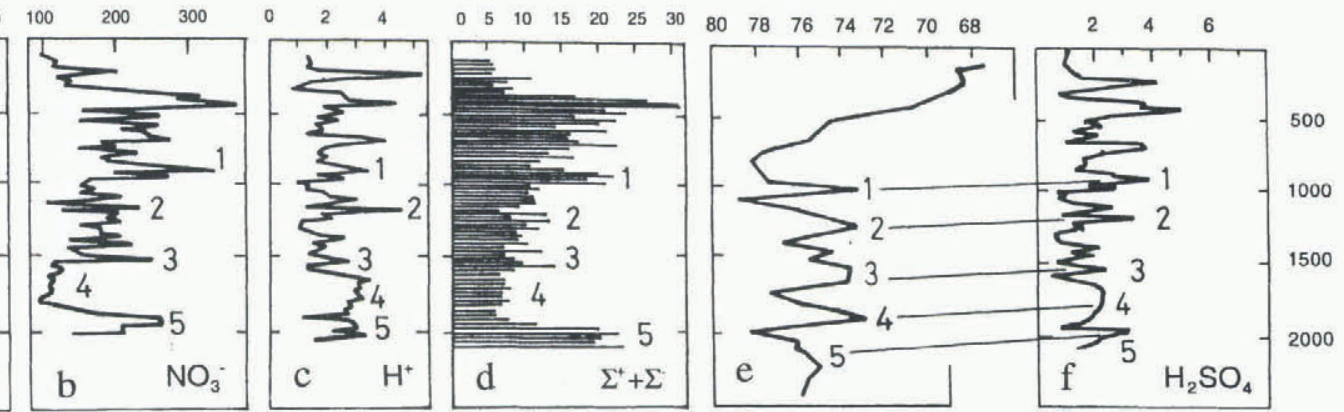

Fig. 4. Chemical, acidity and PRC profiles along the Vostok ice core. (a) Sulphate concentration (b) nitrate concentration, (c) acidity value, (d) ionic balance, (e) PRC from RES data (record no. 557, Figs 2 and 3), ( $f$ ) $\mathrm{H}_{2} \mathrm{SO}_{4}$ concentration, calculated by subtracting the total $\mathrm{SO}_{4}^{-2}$ amount by the contribution of sea salt, $\mathrm{Na}_{2} \mathrm{SO}_{4}$ and $\mathrm{CaSO}_{4}$. Graphs $a-d$ and f are adapted from

Legrand and others (1988). 
verse (Fig. 3). By analyzing the Z-scope reflections from directly beneath the station, the qualitative radio-echo layer signal from the Vostok ice-core site can be established.

\section{VOSTOK ICE-CORE INFORMATION}

It is likely that RES reflections are caused by layers of high acidity and therefore high electrical conductivity (Millar, 1982). Acidity itself is related to the chemical composition of the ice. Since the conductivity profile along the Vostok ice core has not been established, we compare our PRC calculations with the ionic and acidity signal measured from the core (e.g. Legrand and others, 1988). Variations in (i) sulphate concentration $\left(\mathrm{SO}_{4}{ }^{2-}\right)$, (ii) nitrate concentration $\left(\mathrm{NO}_{3}{ }^{-}\right)$, (iii) acidity (observed $\mathrm{H}^{+}$concentration), (iv) ionic balance (total ionic budget in $\mu \mathrm{Eql}^{-1}$ ) and $(\mathrm{v}) \mathrm{H}_{2} \mathrm{SO}_{4}$ (a compound related to volcanic-derived products) with depth are linked to the PRC and Z-scope signals from Vostok station in Figure 4. These independent chemical, acid and ionic signals show a reasonable depth correlation with each other, where five depth-dependent maxima are identifiable (Fig. 4). Layers one (at $900 \mathrm{~m}$ ), two (at $1240 \mathrm{~m}$ ), three (at $1550 \mathrm{~m}$ ) and five $(2100 \mathrm{~m})$ correlate well across all ice-core information (Fig. 4). However, layer four (at 1700$1800 \mathrm{~m}$ ) is not observable on the $\mathrm{SO}_{4}{ }^{2-}$ and $\mathrm{NO}_{3}{ }^{-}$records.

\section{COMPARING RES AND ICE-CORE DATA}

Prominent acid layers (and therefore the RES PRC signal), and other ice layers that form the palaeoenvironment record, are similar in that they are spatially continuous over the ice sheet and deposited at discrete intervals. However, measurements in the two datasets are independent of each other. Thus, we can consider the RES signal an independent stratigraphic control on the ice-core palaeoenvironment data.
We compare the ice-core chemical signature with (1) Zscope RES data from directly over Vostok station and (2) PRC RES information derived from A-scope record no. 557 (Fig. 2). For the case of Z-scope data, prominent internal reflectors compare very well with the depth locations of $\mathrm{H}_{2} \mathrm{SO}_{4}$ peaks (Fig. 5). From this correlation we conclude that radio-echo maxima are related to the peaks in the icecore acidity and chemical signature.

The PRC record indicates five distinct internal layers (at 1000, 1300, 1600, 1900 and 2100 m; Figs 2 and 4). Similarly, the ice-core chemical record shows five distinct acid horizons (at 900, 1200, 1500, 1800 and $2000 \mathrm{~m}$; Fig. 4). If these two datasets are related, then there is an apparent offset of $100 \mathrm{~m}$ between internal layers at Vostok and the location of the PRC record (CBD 557, Fig. 1). There are two possible explanations for a mismatch between ice-core acidity peaks and the prominent internal radio-echo layers. The first is that the two datasets are unrelated and no match should be expected. The second is that the two datasets are directly related, and the difference between the ice depths at which they occur can be assigned to general folding of internal layers from the ice-core site (where the acid measurements were taken) and $\sim 5 \mathrm{~km}$ southwest of Vostok station (where the PRC data were collected). Evidence to support the latter explanation exists in the Z-scope data from Vostok station (Fig. 3), where the internal reflectors can be observed to undulate by around $100 \mathrm{~m}$ of vertical displacement over a distance of $\sim 5 \mathrm{~km}$.

Attention is drawn to the correlation between the RES layering and the $\mathrm{H}_{2} \mathrm{SO}_{4}$ record (Legrand and others, 1988). Major volcanic events are thought to disturb the $\mathrm{H}_{2} \mathrm{SO}_{4}$ signal strongly (Legrand and Delmas, 1987; Legrand and others, 1988). Therefore, the $\mathrm{H}_{2} \mathrm{SO}_{4}$ maxima in the ice core are probably related to volcanic events. Correlation between our RES layering and the $\mathrm{H}_{2} \mathrm{SO}_{4}$ supports the link between RES layering and volcanic deposits (Figs 4 and 5). a

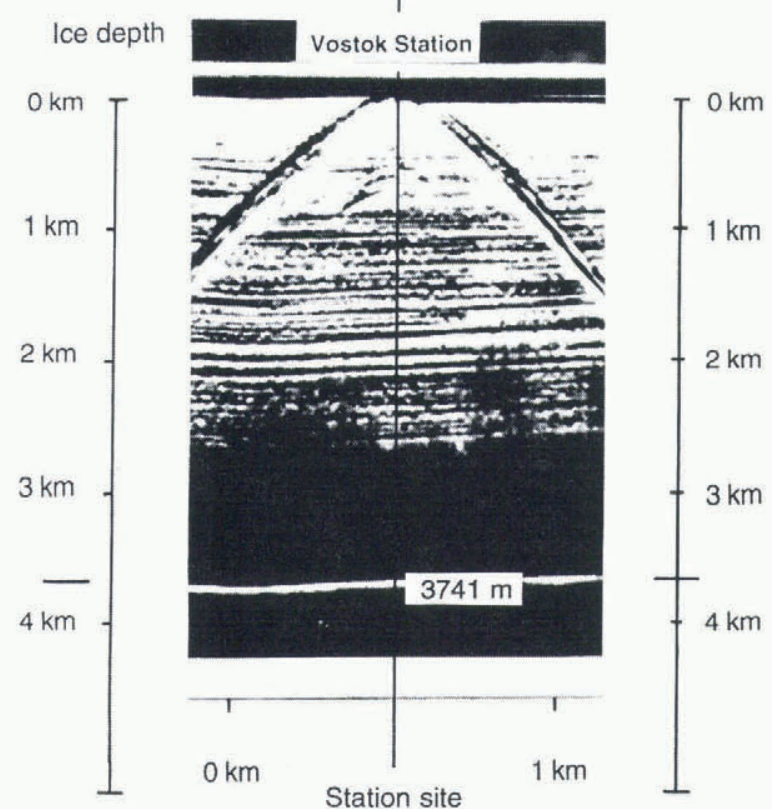

b

Prominent radio-echo layers

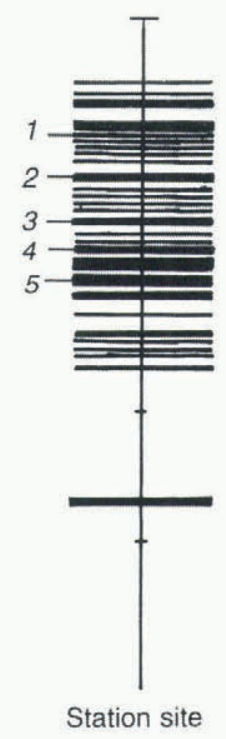

C

Ice core

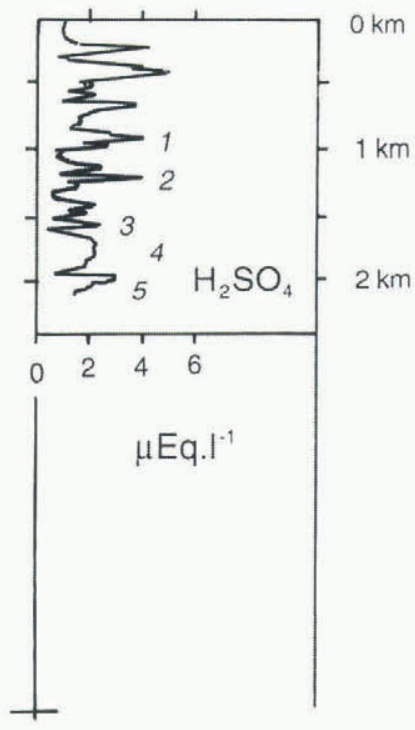

Fig. 5. Comparison between ice-core and RES Z-scope data from the Vostok station site. (a) RES data from Vostok station. The location of the station is established by the radio-wave surface reflections from the station buildings (as in Fig. 3). (b) A representation of distinct internal layers from directly beneath Vostok station. (c) The ice-core $\mathrm{H}_{2} \mathrm{SO}_{4}$ record. Note that five prominent layers identified in the Z-scope can be correlated well with the ice-core $\mathrm{H}_{2} \mathrm{SO}_{4}$ record. 


\section{ANALYSIS OF Z-SCOPE WITH RESPECT TO ORIENTATION OVER VOSTOK STATION}

Flight 009/1977 passed over Vostok station four times (Fig. 1). The beamwidth of the RES signal, perpendicular to the direction of the aircraft, was of the order of a few degrees. Consequently, as the aircraft banked before and/or after each pass of the station, $\mathrm{e} / \mathrm{m}$ reflections from the ice sheet were lost (Fig. 3). However, RES data, penetrating to the ice-sheet base, were recorded when over the station since the aircraft had levelled off at these positions.

The reflection of $\mathrm{e} / \mathrm{m}$ radiation from a dielectric boundary may be influenced by the polarisation of the $\mathrm{e} / \mathrm{m}$ signal. Flight 009/1977 recorded RES data over Vostok station at CBDs 700, 710, 720 and 730 (Fig. 3) along bearings of $240^{\circ}$, $155^{\circ}, 60^{\circ}$ and $315^{\circ}$ (Fig. 1). These data provide an opportunity to examine how e/m reflections may be altered by antenna orientation. The antenna was similarly aligned on the first and third passes and on the second and fourth passes over Vostok station. Thus, there are two sets of data, recorded at approximately perpendicular alignments, from which to assess the change in RES signal with orientation. There are two points to consider: the first is how RES data vary within two recordings along approximately similar orientations, and the second is to determine the change in two RES signals recorded at $90^{\circ}$ to each other.

Qualitatively, the appearance of RES data recorded along the same orientation (at CBDs 710 and 730, and 700 and 720) is similar (Fig. 3). For the former two passes over Vostok station (at $155^{\circ}$ and $315^{\circ}$ ), individual internal radioecho layering is evident and clear, with little convergence/ divergence of layers. However, the second pair (orientations at $60^{\circ}$ and $240^{\circ}$ ) shows a more noisy signal, with some converging of individual layering. We conclude from this simple analysis that polarisation effects may occur within RES data. In the absence of A-scope information and time-dependent power return data for individual layers (ESM data) for flight 009/1977, we are unable to make a more quantitative analysis of this phenomenon.

Although the quality of Vostok RES data is related to flight orientation (Fig. 3), a large number of continuous internal reflectors can be identified in all passes over the station. For example, a strong reflector located at $\sim 2000 \mathrm{~m}$ can be observed in all the data directly over the station (Fig. 3). Moreover, this layer (identified on the PRC records as layer five; Fig. 2), can be traced continuously from Vostok station to location Y (Fig. 3). Thus, polarisation effects (or inhomogeneity of the ice layers) do not alter our analysis of the RES signal at Vostok station.

\section{GONCLUSIONS}

We have identified five strong internal radio-echo layers from analysis of A-scope and Z-scope data from Vostok sta- tion (Figs 2 and 3). The radio-echo layers were compared with Vostok ice-core chemical information, such as acidity and ionic balance (Legrand and others, 1988). In doing so, we have indicated that internal reflectors may be caused by variation in ice chemistry. In particular, we demonstrate the relationship between radio-echo layering and the $\mathrm{H}_{2} \mathrm{SO}_{4}$ record. These layers correlate reasonably well in depth with chemical signals in the Vostok ice core that are indicative of high acidity. This is because high acidity enhances the electrical conductivity, thus producing a pronounced increase in the dielectric constant. The $\mathrm{H}_{2} \mathrm{SO}_{4}$ chemical signal is likely to derive from an aerosol product, deposited widely across Antarctica, that arose from volcanic activity (Millar, 1982; Legrand and Delmas, 1987). Since internal radio-echo layering is related to discrete volcanic events rather than to palaeoclimate, it should represent an independent signal that could aid in the correlation between ice cores.

\section{ACKNOWLEDGEMENTS}

Funding for this project was provided by U.K. Natural Environment Research Council grant GR9/2532 to M.J.S. and J.A.D. Assistance was given to R.H. by the Trans-Antarctic Association. We thank the Director of SPRI for his support of this project. We also thank V. Morgan and two anonymous referees for constructive reviews.

\section{REFERENCES}

Barnola, J. M., D. Raynaud, Ye. S. Korotkevich and C. Lorius. 1987. Vostok ice core provides 160,000-year record of atmospheric $\mathrm{CO}_{2}$. Nature, $329(6138), 408-414$.

Harrison, C. H. 1973. Radio echo sounding of horizontal layers in ice. $f$. Glaciol., 12(66), 383-397.

Hvidberg, C. S., D. Dahl-Jensen and E. D. Waddington. 1997. Ice flow between the GRIP and GISP2 boreholes in central Greenland. f. Geophys. Res., 102 (Cl2), 26,851-26,859.

Kapitsa, A. P., J. K. Ridley, G. de Q. Robin, M.J. Siegert and I. Zotikov. 1996. A large deep freshwater lake beneath the ice of central East Antarctica. Nature, 381 (6584), 684-686.

Legrand, M. R. and R. J. Delmas. 1987. A 220-year continuous record of volcanic $\mathrm{H}_{2} \mathrm{SO}_{4}$ in the Antarctic ice sheet. Nature, 327 (6124), 671-676.

Legrand, M. R., C. Lorius, N. I. Barkov and V. N. Petrov. 1988. Vostok (Antarctica) ice core: atmospheric chemistry changes over the last climatic cycle (160,000 years). Atmos. Environ., 22 (2), 317-331.

Legrand, M., C. Feniet-Saigne, E. S. Saltzman, C. Germain, N. I. Barkov and V. N. Petrov. 1991. Ice-core record of oceanic emissions of dimethylsulphide during the last climate cycle. Nature, 350 (6314), 144-146.

Millar, D. H. M. 1981. Radio-echo layering in polar ice sheets and past volcanic activity. Nature, 292(5822), 441-445.

Millar, D. H. M. 1982. Acidity levels in ice sheets from radio echo-sounding. Ann. Glaciol., 3, 199-203.

Moore, J. C. 1988. Dielectric variability of a $130 \mathrm{~m}$ Antarctic ice core: implications for radar sounding. Ann. Glaciol., 11, 95-99.

Paren, J.G. 1981. Correspondence. Reflection coefficient at a dielectric interface. J. Glaciol., 27(95), 203-204.

Robin, G. de Q., S. Evans and J. T. Bailey. 1969. Interpretation of radio echo sounding in polar ice sheets. Philos. Trans. R. Soc. London, Ser. A, 265(1166), $437-505$. 